\title{
Improved outcomes in patients with chronic obstructive pulmonary disease treated with salmeterol compared with placebo/usual therapy: results of a meta-analysis

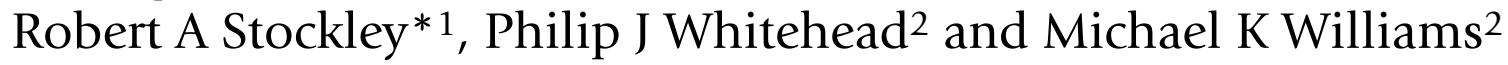

Address: ${ }^{1}$ Queen Elizabeth Hospital, Birmingham, UK and ${ }^{2}$ GlaxoSmithKline, Greenford Road, Greenford, Middlesex UB6 OHE, UK

Email: Robert A Stockley* - r.a.stockley@bham.ac.uk; Philip J Whitehead - philip.whitehead@gsk.com; Michael KWilliams - michael.k.williams@gsk.com

* Corresponding author

Published: 29 December 2006

Respiratory Research 2006, 7:147 doi:10.1 |86/1465-992/-7-147
Received: 14 November 2006

Accepted: 29 December 2006

This article is available from: http://respiratory-research.com/content/7/I/I47

(c) 2006 Stockley et al; licensee BioMed Central Ltd.

This is an Open Access article distributed under the terms of the Creative Commons Attribution License (http://creativecommons.org/licenses/by/2.0), which permits unrestricted use, distribution, and reproduction in any medium, provided the original work is properly cited.

\begin{abstract}
Background: Several studies have demonstrated that long-acting $\beta_{2}$-agonists such as salmeterol are beneficial in chronic obstructive pulmonary disease (COPD). A meta-analysis was therefore conducted to review studies in COPD to provide pooled estimates of the effect of salmeterol 50 mcg taken twice daily in addition to usual therapy on several clinically relevant endpoints, when compared with placebo/usual therapy.
\end{abstract}

Methods: An extensive search of literature and clinical trial databases was conducted using the terms salmeterol, COPD, chronic, obstructive, bronchitis and emphysema. Nine randomized, double-blind, parallel-group, placebo-controlled trials of $\geq 12$ week duration with salmeterol $50 \mathrm{mcg}$ bid treatment in COPD were included ( $>3500$ patients), with a further 14 trials excluded due to study design or reporting timelines. All patients were included, and a sub-group of subjects (84\%) with poorly reversible COPD were considered separately. Statistical testing was carried out at the $5 \%$ level, except for interaction testing which was carried out at the $10 \%$ level.

Results: Patients treated with salmeterol over 12 months were less likely to withdraw early from the studies ( $19 \%$ patients compared with $25 \%$ on their current usual therapy, $\mathrm{p}<0.00 \mathrm{I}$ ), less likely to suffer a moderate/severe exacerbation $(34 \%$ compared with $39 \%, p<0.000 I)$ and had a greater increase in average $\mathrm{FEV}_{1}(73 \mathrm{~mL}$ difference vs placebo/usual therapy, $\mathrm{p}<0.000 \mathrm{I})$. Similar differences were found at 3 and 6 months. At all time points, more patients experienced an improvement in health status and also a greater change with salmeterol than with placebo/usual therapy $(p<0.002)$. There was no evidence of tachyphylaxis to salmeterol over 12 months.

Conclusion: The meta-analysis confirmed clinically and statistically significant, sustained and consistent superiority of salmeterol $50 \mathrm{mcg}$ bid over placebo/usual therapy on a broad range of outcome measures.

\section{Background}

Chronic obstructive pulmonary disease (COPD) is a debilitating progressive multi-component disease charac- terised by airflow limitation that is not fully reversible [1]. COPD is associated with an inflammatory response in the airways, together with airway obstruction, mucociliary 
dysfunction and structural changes within the lungs [1]. These features result in combinations of symptoms and physiological changes that affect the ability of patients to function, and ultimately influence survival. In addition to chronic symptoms, patients with COPD may experience acute exacerbations, which have a major impact on morbidity, mortality and healthcare utilization [2-4].

The burden of COPD is considerable. Currently, COPD is the fourth leading cause of mortality worldwide, predicted to rise to the third leading cause by 2020 [5]. As a disabling condition that affects the physical and social functioning of the sufferer, COPD is also associated with considerable impact on health status. Thus by 2020 , COPD is projected to be the fifth leading cause of disability [5].

With increasing understanding of the pathophysiology of COPD, a number of pharmacological and surgical approaches to management of the disease have been developed. International management guidelines recommend that the goals of treatment should be to prevent and control symptoms, prevent and reduce the severity of acute exacerbations, improve lung function, and improve health status [1]. In the design of clinical trials, endpoints that are considered to be clinically important have also been clarified recently, and include withdrawal rates from studies, exacerbation rates, lung function (pre and postbronchodilator $\mathrm{FEV}_{1}$ ) and health status [6].

More recent therapies for COPD include salmeterol, a long-acting inhaled $\beta_{2}$-agonist, anticholinergic agonists such as tiotropium bromide and others such as Phosphodiesterase 4 inhibitors which have resulted in a large body of published data assessing the efficacy from numerous clinical trials. These trials have varied considerably in terms of inclusion and exclusion criteria, endpoints and study duration and often restrict other therapies in order to demonstrate any advantage of the new therapy which provides an impression of efficacy that may not reflect the "real world". However, there have been several controlled trials of salmeterol therapy added to usual treatment in COPD which more likely reflects usual prescribing practice. The opportunity was therefore taken to review these studies in the light of current knowledge about relevant clinical endpoints.

The aim of the subsequent meta-analysis of patients with COPD was to provide pooled estimates of the effect of salmeterol $50 \mathrm{mcg}$ taken twice daily when compared with placebo/usual therapy on several clinically relevant endpoints.

\section{Methods}

\section{Data sources}

An extensive literature search was conducted through the database, Medline, using the terms salmeterol, COPD, chronic, obstructive, bronchitis and emphysema, with the full reference (where available) used to review the study results. The same terms were also used to search the GlaxoSmithKline clinical trial tracking system. All completed studies reported by 7 January 2002 were included in the analysis.

\section{Study selection}

Studies were included in the analysis if they met the following inclusion criteria:

1) Randomized, double-blind, parallel-group, placebocontrolled trial of at least 12 weeks duration

2) Data was available on at least one of the specified endpoints (withdrawal rate, moderate/severe exacerbations, pre-bronchodilator $\mathrm{FEV}_{1}$ and health status)

3) Patients were non-asthmatic adults with stable COPD and no recent infections, exacerbations or hospitalisations in the previous 4 weeks (studies including subjects with other severe conditions, including cardiac, liver and renal disease were also excluded)

4) At least two treatment arms: salmeterol $50 \mathrm{mcg}$ bid and placebo (with or without usual therapy).

Based on these criteria, nine studies were identified for inclusion in the meta-analysis [7-16], with 14 studies identified but not included in the analysis due to their crossover design, short treatment duration, or incomplete status at the cut-off date (Figure 1). All the studies that met the criteria had been sponsored by GlaxoSmithKline.

\section{Data extraction}

Analysis of individual subject data was performed in all cases. Data relating to two populations were extracted, corresponding to the American Thoracic Society [17] and European Respiratory Society [18] definitions of COPD, respectively:

- Intention to treat (ITT) population, which consisted of all randomized subjects taking $\geq 1$ dose of study medication

- Poorly reversible (PR) population, which was defined as the sub-group of subjects with reversibility $<10 \%$ of predicted $\mathrm{FEV}_{1}$ following inhalation of albuterol $400 \mathrm{mcg}$ or equivalent. 


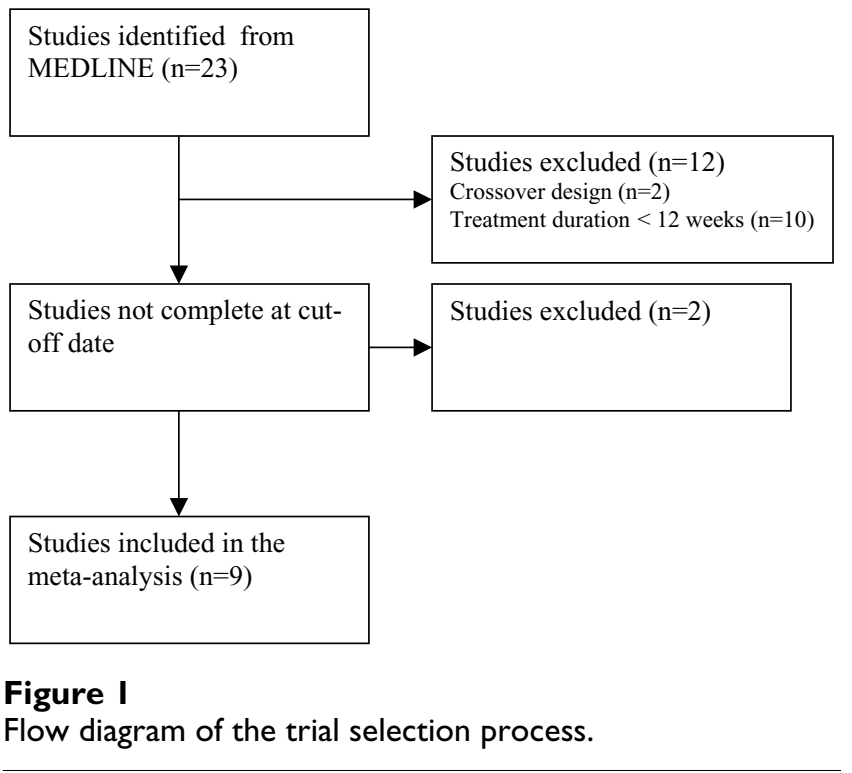

Information on a number of covariates was also extracted to facilitate subgroup analysis, including age of subjects, baseline $\mathrm{FEV}_{1}$, body mass index, duration of COPD, smoking history and use of regular inhaled and oral corticosteroids at baseline.

Analysis of data on $\mathrm{FEV}_{1}$ and health status included the actual data recorded at each time point (Observed), and, to account for withdrawals, the last observation carried forward to each time point (LOCF). LOCF was the primary analysis and is presented here. There were no meaningful differences between LOCF and Observed analyses.

Analyses were conducted for treatment of 3, 6 and 12 months duration. The visit identifier on the study database was used to allocate each observation to a time point. In the study reported by Stockley et al. $[15,16]$, data for the 3-and 6-month endpoints were calculated by linear interpolation of data from the 1- and 4-month assessments, and 4- and 7-month assessments, respectively, as 3- or 6-month assessments were not performed.

The recording of exacerbations data differed from study to study. To make the data comparable, case record forms were examined and consistent definitions applied (mild: managed by the subject by modifying the dose of COPD medication; moderate: required the use of additional oral corticosteroids and/or antibiotics; severe: required hospitalisation) [19]. For the $\mathrm{FEV}_{1}$ and reversibility data, the mean pre-treatment values were used as the baseline. In the European studies [10,13-16], the St George's Respiratory Questionnaire (SGRQ) was used to assess health status, whereas studies conducted in the USA $[8,9,11,12]$ used the Chronic Respiratory Disease Questionnaire (CRDQ). To combine data from these studies, the measure used was the proportion of subjects achieving a clinically significant improvement in health status (4-point or more decrease from baseline in the total score for the SGRQ; 10-point or greater increase in total score for the CRDQ) [20-23]. In addition, the change from baseline has been expressed as a percentage of the clinically relevant difference for each measure in order to combine the information from both types of questionnaire. The study reported by van Noord [7] did not include a health status assessment and was thus excluded from the analysis of this endpoint.

\section{Data analysis}

All analyses were performed, using SAS 8.1 on a Unix environment. The primary model was fixed effects, with testing for interaction between treatment and study indicator to see if this was appropriate for each analysis. A random effects model was fitted if there was heterogeneity. Statistical testing was carried out at the 5\% level, except for interaction testing which was carried out at the $10 \%$ level.

The analysis examined only moderate and severe exacerbations, due to their greater clinical significance and objectivity (assessment by physician required). Proportional hazards modelling was used to estimate the difference in time to first exacerbation for individual studies and for all studies, and calculate the relative risk between treatments. This approach was also used to analyse time to withdrawal from studies. For health status, a repeated measure analysis was carried out. Summary statistics are presented as means or percentages, as relevant, including standard deviations (SD).

\section{Results}

\section{Study characteristics}

Table 1 summarises the nine studies included in the metaanalysis, together with the main eligibility criteria. The study reported by Boyd [10] included a criterion for reversibility to albuterol $(5-15 \%$ change in baseline $\left.\mathrm{FEV}_{1}\right)$, as did studies reported by Calverley and Stockley [14-16] ( $\leq 10 \%$ change in predicted $\left.\mathrm{FEV}_{1}\right)$. The study reported by Stockley $[15,16]$ also included a requirement for two or more moderate or severe exacerbations in the previous year, while the study reported by Calverley [14] required at least one exacerbation per year for the previous 3 years. Studies reported by Mahler, Hanania, Calverley and Boyd $[10-12,14]$ included a requirement for cough and phlegm for 3 or more months a year during the previous 2 years, while studies reported by Chapman and Stockley $[13,15,16]$ specified sputum for 3 or more months a year in the previous 2 or more years. All studies specified a smoking history of at least 10 pack years, with 
studies reported by Mahler and Hanania $[11,12]$ requiring a history of at least 20 pack years.

In addition to the study medication and placebo, usual COPD therapy was continued in most of the trials, generally with the requirement that doses were kept stable. Short-acting bronchodilators were allowed in all trials, but not as a combination with other drugs except in the study reported by Chapman [13]. Antibiotics for acute exacerbations were permitted in all trials. Regular treatment with oral and/or inhaled corticosteroids was permitted in six of the trials $(67 \%)$, while anticholinergic therapy could be continued in four trials (44\%) and methylxanthines in seven trials $(78 \%)$. Consequently, the analysis is effectively a comparison of adding salmeterol or placebo to usual therapy and so more closely approximates the situation in normal clinical practice.

Salmeterol and placebo were administered via Chlorofluorocarbon containing pressurised metered dose inhaler in four studies [7-10] whereas the Diskus ${ }^{\mathrm{TM}} / \mathrm{Accu}-$ haler $^{\mathrm{TM}}$ dry powder inhaler was used in all other studies [11-16]. Both devices are licensed to deliver the same dose of salmeterol (50 mcg bid) in COPD.

A total of 3580 patients were included in the analysis, with 2565 males (72\%). Demographic and baseline characteristics were well-matched between treatment groups, with an average age of 63.8 years $(\mathrm{SD} \pm 8.8)$, baseline $\mathrm{FEV}_{1}$ of $1.29 \mathrm{~L}( \pm 0.47)$ which was $45.2 \%$ predicted $( \pm 13.8)$ and an average baseline reversibility of $5.96 \%$ predicted $( \pm$
$5.2 \%)$. Most subjects $(2474 ; 69 \%)$ had a diagnosis of COPD of 5 or more years duration, $46 \%$ were using inhaled corticosteroids prior to study start and $4 \%$ were using oral corticosteroids. Mean smoking history was 49.1 pack years $( \pm 29.6)$. The characteristics of the PR population $(84 \%$ of total) were not significantly different to the ITT population.

\section{Withdrawal from studies}

For all three time periods studied (1-3, 1-6 and 1-12 months), there was a consistent and highly statistically significant reduction in the percentage of early withdrawals in the ITT population treated with salmeterol compared to usual therapy, as summarised in Figure 2 ( $p<$ 0.0001 at all time points). Results were similar with the PR population. In both populations (ITT and PR), fewer patients on salmeterol withdrew over months 1-6 if they had a higher body mass index (BMI). In the ITT population, the risk of withdrawal following treatment with salmeterol was reduced by $35 \%$ in patients with $\mathrm{BMI}>27$ (p $=0.0017)$ and by $55 \%$ in patients with BMI $>24-<27(\mathrm{p}<$ 0.0004 ), but only $10 \%$ for patients with $\mathrm{BMI}<24$ ( $\mathrm{p}=$ 0.3971).

\section{Exacerbations}

Survival analysis showed that use of salmeterol delayed the time to first exacerbation (Figure 3). At each time point analysed, there was a consistent and highly significant reduced risk of moderate or severe exacerbation in the ITT population treated with salmeterol compared with usual therapy (28\% during months $1-3,24 \%$ during

Table I: Studies included in the analysis

\begin{tabular}{|c|c|c|c|c|c|c|c|c|c|c|c|}
\hline \multirow[t]{2}{*}{ Study } & \multirow[t]{2}{*}{$\begin{array}{l}\text { Duration } \\
\text { (weeks) }\end{array}$} & \multicolumn{2}{|c|}{$\begin{array}{l}\text { No. in ITT (PR) } \\
\text { populations }\end{array}$} & \multicolumn{4}{|c|}{ Main eligibility criteria } & \multicolumn{4}{|c|}{ COPD medication allowed during the study } \\
\hline & & Salmeterol & Placebo & Definition & Age (yrs) & $\begin{array}{l}\mathrm{FEV}_{\mathrm{I}}(\% \\
\text { predicted } \% \\
\text { absolute } \\
\text { value })\end{array}$ & $\mathrm{FEV}_{\mathrm{I}} / \mathrm{FVC}$ & OCS & ICS & Antichol. & $M X$ \\
\hline van Noord & 12 & $49(40)$ & $50(44)$ & ATS & $40-75$ & $\begin{array}{c}\leq 65 \% \& \geq \\
0.75 \mathrm{~L}\end{array}$ & $\leq 60 \%$ & Yes & $\leq \mathrm{I} \mathrm{mg} /$ day FP* & No & Yes \\
\hline Rennard & 12 & $131(84)$ & $133(85)$ & ATS & $\geq 35$ & $\begin{array}{c}\leq 65 \% \&> \\
0.7 \mathrm{~L} \text { or } \geq 40 \% \\
\&<0.7 \mathrm{~L}\end{array}$ & $\leq 70 \%$ & $\leq 10 \mathrm{mg}$ prednisolone* & Yes & No & No \\
\hline Mahler & 12 & $135(78)$ & $143(90)$ & ATS & $\geq 35$ & $\begin{array}{c}\leq 65 \% \&>0.7 \mathrm{~L} \\
\text { or } \geq 40 \% \& \& \\
<0.7 \mathrm{~L}\end{array}$ & $\leq 70 \%$ & $\leq 10 \mathrm{mg}$ prednisolone* & Yes & No & No \\
\hline Boyd & 16 & $228(221)$ & $227(215)$ & ERS & $40-75$ & $\leq 70 \% \&>0.6 \mathrm{~L}$ & $\leq 60 \%$ & Yes & Yes & Yes & Yes \\
\hline Mahler & 24 & $164(105)$ & $185(130)$ & ATS & $\geq 40$ & $\begin{array}{c}<65 \% \&>0.7 \mathrm{~L} \\
\text { or }>40 \% \& \& \\
\leq 0.7 \mathrm{~L}\end{array}$ & $\leq 70 \%$ & No & No & No & Yes \\
\hline Hanania & 24 & $176(112)$ & $185(118)$ & ATS & $\geq 40$ & $\begin{array}{c}<65 \% \&>0.7 \mathrm{~L} \\
\text { or }>40 \% \& \& \\
\leq 0.7 \mathrm{~L}\end{array}$ & $\leq 70 \%$ & No & No & No & Yes \\
\hline Chapman & 24 & 201 (I73) & $206(|7|)$ & ERS & $\geq 40$ & $\leq 85 \%$ & $\leq 70 \%$ & Yes & Yes & Yes & Yes \\
\hline Calverley & 52 & $372(37 I)$ & 361 (359) & ERS & $40-79$ & $\geq 25 \%-\leq 70 \%$ & $\leq 70 \%$ & Exacerbations & No & Yes & Yes \\
\hline Stockley & 52 & $316(292)$ & $318(304)$ & ERS & $\geq 40$ & $<70 \%$ & Not stated & Exacerbations & $\leq \mathrm{I} \mathrm{mg} /$ day FP* & Yes & Yes \\
\hline Pooled & & $1772(1476)$ & $1808(1516)$ & & & & & & & & \\
\hline
\end{tabular}

* or equivalent; ATS: American Thoracic Society; ERS: European Respiratory Society; FEV , forced expiratory volume in one second; FVC, forced vital capacity; OCS: oral corticosteroids; ICS: inhaled corticosteroids; Antichol: anticholinergics; MX: methylxanthines. FP: fluticasone propionate 


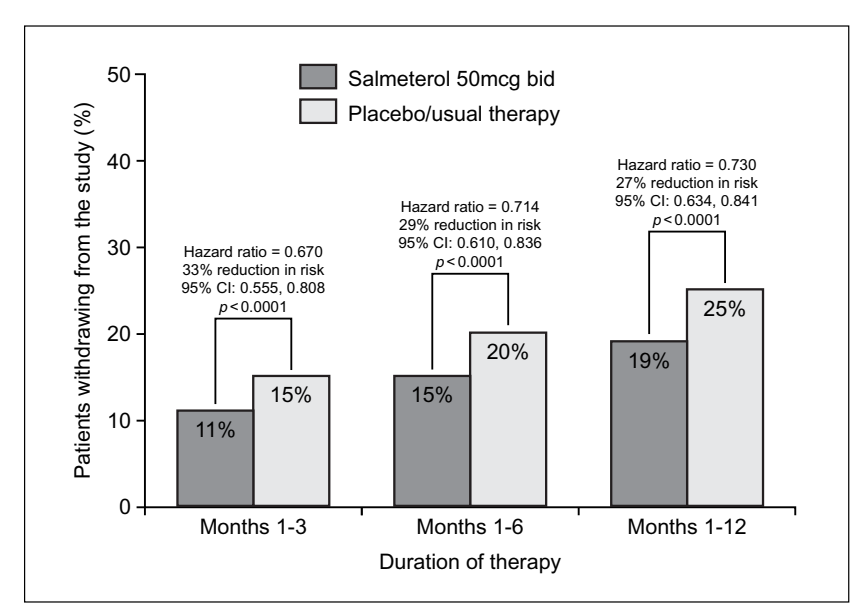

Figure 2

Cumulative withdrawal from clinical studies (pooled results from Intent To Treat population).

months $1-6$ and $22 \%$ during months $1-12, \mathrm{p}<0.0001)$ Results were similar with the PR population (20-25\% reduction in risk compared with usual therapy, $\mathrm{p}=$ 0.0002). All types of subjects showed similar level of reduced exacerbation risk irrespective of their disease severity, smoking history, duration of COPD or current therapy.

\section{Lung function}

There was a consistent and statistically significant increase in average pre-bronchodilator $\mathrm{FEV}_{1}$ with salmeterol treatment compared with usual therapy, ranging from 73-86 $\mathrm{mL}$ over the three time periods assessed (Table 2, Figure 4 ). This corresponded to increases of 3.2\% (Figure 5), $3.0 \%$ and $3.0 \%$ as a percentage of predicted $\mathrm{FEV}_{1}$ after 3 ,

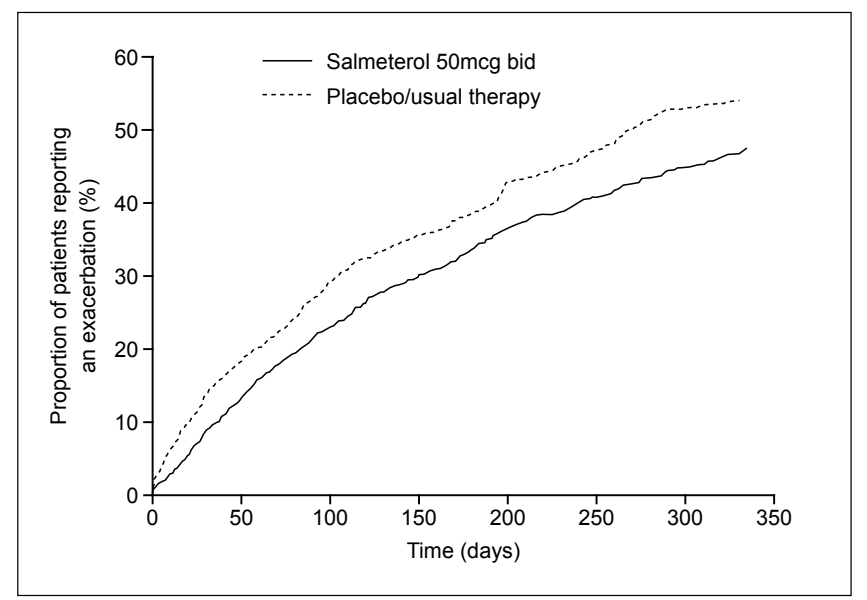

Figure 3

Survival analysis of time to first exacerbation (pooled results from Intent To Treat population).
6 and 12 months, respectively $(\mathrm{p}<0.0001)$. Results were comparable in the PR population (increase in pre-bronchodilator $\mathrm{FEV}_{1}$ of $68-74 \mathrm{~mL}$ or $2.9-3 \%$ percent predicted). The youngest subjects ( $<60$ years; $n=1001)$ had a consistently greater difference in favour of salmeterol (range 111-113 $\mathrm{mL}, \mathrm{p}<0.001)$ than the oldest $(>70$ years, range 43-59 mL, $\mathrm{p}=0.0083$; $\mathrm{n}=826$ ), with intermediate values for the subjects aged 60-69 years $(\mathrm{n}=$ 1316) Previous (not concurrent) use of inhaled corticosteroids was associated with smaller treatment differences at most time points, possibly due to the greater severity of COPD in subjects when ICS are more likely to be prescribed. The average pre-bronchodilator $\mathrm{FEV}_{1}$ for patients on placebo/usual therapy showed a decrease below baseline at all time points (Figure 4).

\section{Health status}

There was a consistent, statistically significant and clinically meaningful improvement in health status with salmeterol compared with usual therapy (Table 3). Health status improved beyond the clinically significant thresholds with salmeterol therapy in about half of the ITT population (46\%) compared with 38\% experiencing such an improvement with usual therapy ( $\mathrm{p}<0.0001)$. Similar results were found in the PR population (45\% compared with 39\%, p < 0.0016). Among the ITT population, the greatest benefits with salmeterol were noted in younger subjects $(11 \%$ difference in those aged $<60$ years, $\mathrm{p}=$ 0.007 vs $3-4 \%$ difference for those aged $>70$ years, $\mathrm{p}=$ $0.3649)$ and those with greatest reversibility ( $8 \%$ difference for subjects with $>5 \%$ reversibility, $\mathrm{p}=0.0031$ vs $5 \%$ for those with $<5 \%$ reversibility, $p=0.1587)$. Among those patients completing the SGRQ, the percentage of subjects with a meaningful improvement over 12 months also favoured salmeterol (ITT $46.5 \%$ vs $38.5 \%$, p = 0.0118 ; PR subjects $46.1 \%$ vs $38.9 \%, p=0.024)$. In addition, the change from baseline expressed as a percentage of the clinically relevant difference for each measure (4 point decrease for SGRQ and 10 point increase in CRDQ) at 6 and 12 months is shown in Figure 6 indicating not only that increased numbers of subjects on salmeterol passed the clinically meaningful threshold but that the average increase was also greater.

\section{Discussion}

Evidence from a meta-analysis of randomized, controlled clinical trials is usually considered the most influential in management guidelines because of the large number of patients involved. This meta-analysis included 3580 patients recruited from centres in 34 countries across four continents, and showed consistent and statistically significant superiority of salmeterol $50 \mathrm{mcg}$ bid over placebo/ usual therapy on all outcome measures evaluated after 3 , 6 and 12 months of treatment. Patients were 27-33\% less likely to withdraw early from a study $(\mathrm{p}<0.0001)$ and 
Table 2: Mean difference in pre-bronchodilator FEV, between treatment with salmeterol and with placebo/usual therapy after 3, 6 and 12 months of treatment (intent to treat population).

\begin{tabular}{lrrrrrrr}
\hline Study & No. of subjects & \multicolumn{7}{c}{ Mean treatment effect on pre-bronchodilator FEV $(\mathrm{ml})$} \\
\cline { 2 - 7 } & Salmeterol & Placebo & 3 months & P value & 6 months & P value & 12 months \\
\hline van Noord & 49 & 50 & 108 & 0.0056 & - & - & - \\
Rennard & 131 & 133 & 74 & 0.0027 & - & - & - \\
Mahler & 135 & 143 & 128 & $<0.0001$ & - & - & - \\
Boyd & 228 & 227 & 102 & $<0.0001$ & - & - & - \\
Mahler & 164 & 185 & 96 & $<0.0001$ & 94 & $<0.0001$ & - \\
Hanania & 176 & 185 & 97 & $<0.0001$ & 92 & $<0.0001$ & - \\
Chapman & 201 & 206 & 42 & 0.0278 & 20 & 0.3559 & - \\
Calverley & 372 & 361 & 80 & $<0.0001$ & 91 & $<0.0001$ & - \\
Stockley & 316 & 318 & 81 & $<0.0001$ & 74 & 0.0002 & - \\
Pooled & 1772 & 1808 & 86 & $<0.0001$ & 75 & $<0.0001$ & 96 \\
\end{tabular}

-: not applicable

$22-28 \%$ less likely to suffer a moderate or severe exacerbation $(\mathrm{p}<0.0001)$ when salmeterol rather than placebo was added to usual therapy. Lung function improved by 73-86 $\mathrm{mL}\left(3.0-3.2 \%\right.$ predicted $\left.\mathrm{FEV}_{1}\right)$ and more patients experienced a clinically meaningful improvement in health status when treated with salmeterol compared with placebo/usual therapy ( $46 \%$ vs $38 \%$, p < 0.0001 ).

The results of this meta-analysis are likely to be widely applicable to patients with COPD. Each of the nine studies included was sufficiently powered to detect a predefined difference in one or more of the efficacy measures of interest. Heterogeneity in the results from different trials was observed only for $\mathrm{FEV}_{1}$ during months 1-6, though the degree of departure was small and the results derived from the random effects model did not differ from those of the fixed effects model.

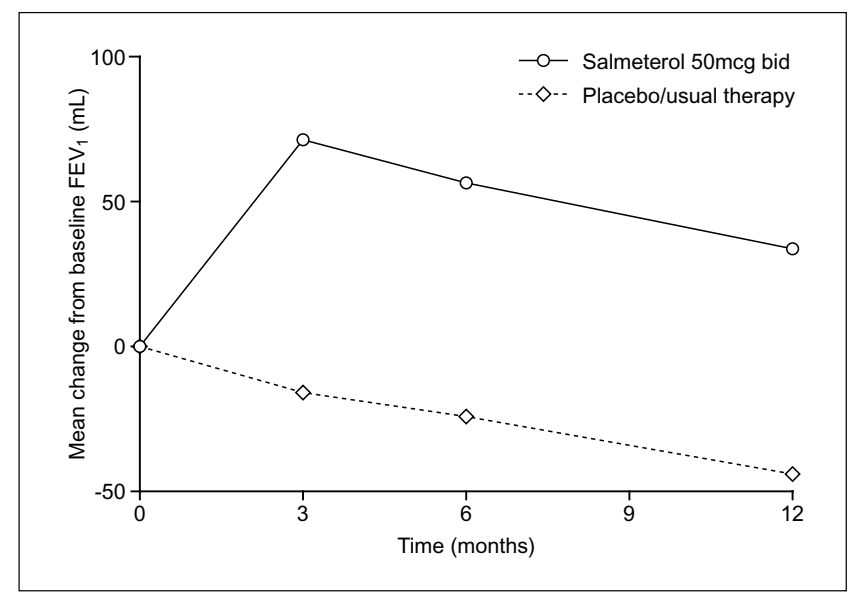

Figure 4

Mean change from baseline $\mathrm{FEV}_{\text {, }}$ (pooled results from Intent To Treat population).
Demographic and baseline characteristics were wellmatched between treatment groups, with the study population reflecting the profile of typical COPD patients. Over half of the subjects had been randomized into studies with duration of 24 weeks or more, and $38 \%$ were recruited into studies of 1 -year duration. Consequently, a reasonable assessment of long-term (6-12 months) efficacy of salmeterol can also be derived from the results of this meta-analysis. The ITT population corresponded to subjects meeting the American Thoracic Society definition of COPD [17], while the subset of subjects with bronchodilator reversibility $<10 \%$ (PR, comprising $84 \%$ of the total population) corresponded to the ERS definition of COPD [18]. Results in the PR population were similar to the ITT population.

Withdrawals from clinical trials of COPD present a considerable problem in analysis and interpretation [24]. A significantly higher withdrawal rate on placebo/usual therapy (due to lack of potential benefits, thereby leaving a subset who may have less severe disease) may bias the results against the treatment. This imbalance between the treatment arms, with placebo/usual therapy results being artificially improved, would therefore reduce apparent treatment benefits. The meta-analysis showed a highly significant difference in the rate of early withdrawal from clinical studies between the treatment groups. Patients receiving salmeterol were up to $33 \%$ less likely to withdraw from studies than those receiving placebo/usual therapy $(\mathrm{p}<0.0001)$. Furthermore, despite the greater withdrawal rate in the control group that may reduce apparent differences between treatments, highly significant treatment benefits with salmeterol were still detected. This suggests that salmeterol provided treatment benefits recognised and valued by patients that outweighed any potential side effects. Indeed, a recent meta-analysis has 


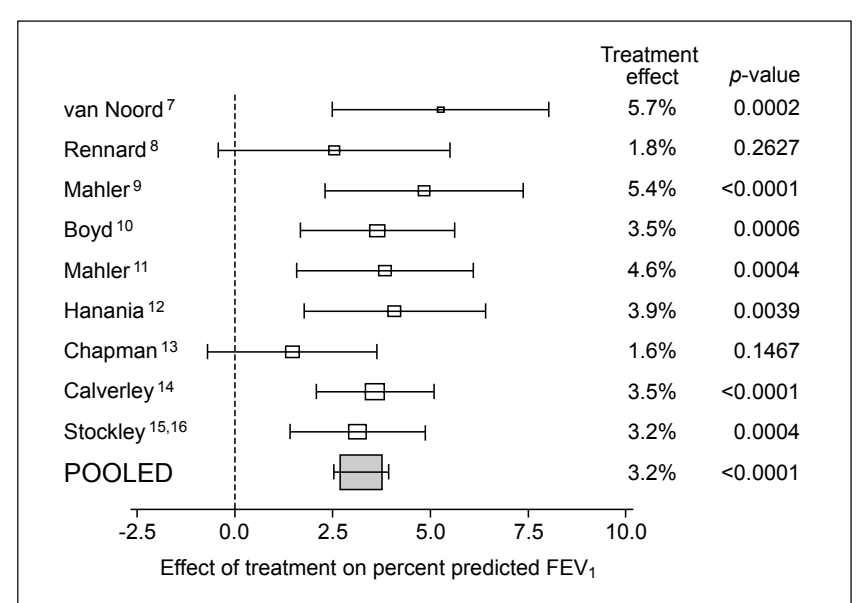

Figure 5

Percent predicted FEV, (Intent To Treat population).

shown a good safety profile for salmeterol [25], supporting this hypothesis.

Lung function improved by 3.2\%, 3.0\% and 3.0\% at 3, 6 and 12 months, respectively, suggesting that there was no tolerance, or decrease of efficacy, over time for up to 1 year of therapy. Some studies [26,27] have suggested that response may decrease with continued use whereas other studies have failed to find evidence of such tolerance $[9,12]$. The current meta analysis supports the latter studies although the reality and clinical relevance of any decrease continue to be an important focus of attention in COPD therapy.

Exacerbations are common in COPD and may have serious consequences $[2,28,29]$. Recovery from exacerbations may take more than a month in around a quarter of patients, or may even be incomplete [30]. A high frequency of exacerbations is associated with a more rapid decline in lung function [31], increased risk of hospitalisation [32] and reduced survival [33], with nearly half of patients hospitalised for a COPD exacerbation dying within 3 years [33]. A regular treatment that reduces the frequency and severity of exacerbations could, therefore, have an impact on both morbidity and survival. The current meta-analysis showed that salmeterol significantly ( $\mathrm{p}$ $<0.0001)$ reduced the risk of experiencing a moderate or severe exacerbation by up to $28 \%$ compared with usual therapy. In addition to the potential patient benefits, this should also reduce medical resource utilization.

COPD is characterised by progressive decline in lung function of around 60-70 ml per year [34,35]. During an exacerbation, lung function falls by an average of $24 \mathrm{ml}$ [30], while a short-term increase of $90 \mathrm{ml}$ in patients with emphysema is sufficient to improve dyspnoea and exercise performance [36]. Consequently, the highly significant improvement in lung function of 73-86 ml observed with salmeterol compared with placebo/usual therapy is likely to be beneficial and clinically meaningful. Importantly, the measurements were made shortly before the next dose of study medication, representing the lowest value in the 12-hour dosing period, so that lung function at other time points could be expected to show a greater treatment difference. The difference between salmeterol and placebo/usual therapy was apparent from the earliest assessment point ( 3 months) and maintained at 6 months and 12 months, indicating that there was no decline in efficacy over this period.

There is increasing recognition that patient-centred outcomes, such as health status, are important in assessing the efficacy of medical interventions for COPD [37]. There was a consistent, statistically significant and clinically detectable improvement in health status in more patients treated with salmeterol than with placebo/usual therapy. A clinically meaningful change with the SGRQ (change in total score of 4 units) corresponds to patients, for example, 'no longer having to walk more slowly than other people, no longer being breathless on getting washed and dressed or on bending over' [38]. These changes are generally more relevant to patients than spirometric changes, although they are likely to reflect changes in the latter. The

Table 3: Proportion of patients experiencing a clinically meaningful change in health status with salmeterol or placebo/usual therapy.

\begin{tabular}{|c|c|c|c|c|c|c|c|}
\hline \multirow[t]{2}{*}{ Time period } & \multicolumn{2}{|l|}{ Salmeterol } & \multicolumn{2}{|l|}{ Placebo } & \multicolumn{3}{|c|}{ Pooled estimate of difference } \\
\hline & No. of subjects & $\begin{array}{l}\% \text { with } \\
\text { meaningful } \\
\text { change }\end{array}$ & No. of subjects & $\begin{array}{l}\% \text { with } \\
\text { meaningful } \\
\text { change }\end{array}$ & $\begin{array}{l}\text { Difference in \% } \\
\text { meaningful } \\
\text { change }\end{array}$ & $95 \% \mathrm{Cl}$ & $P$ value \\
\hline \multicolumn{8}{|c|}{ Intent to treat population } \\
\hline Weeks 8-28 & 1150 & $45.3 \%$ & 1129 & $37.9 \%$ & $7.7 \%$ & $4.6,10.7$ & $<0.0001$ \\
\hline Weeks 8-52 & 1156 & $45.9 \%$ & || $3 \mid$ & $37.9 \%$ & $7.9 \%$ & $5.1,10.7$ & $<0.0001$ \\
\hline \multicolumn{8}{|c|}{ Poorly reversible population } \\
\hline Weeks 8-28 & 934 & $44.6 \%$ & 935 & $38.9 \%$ & $5.4 \%$ & 2.1, 8.8 & 0.0016 \\
\hline Weeks 8-52 & 939 & $45.3 \%$ & 937 & $39.0 \%$ & $5.9 \%$ & $2.8,8.9$ & 0.0002 \\
\hline
\end{tabular}




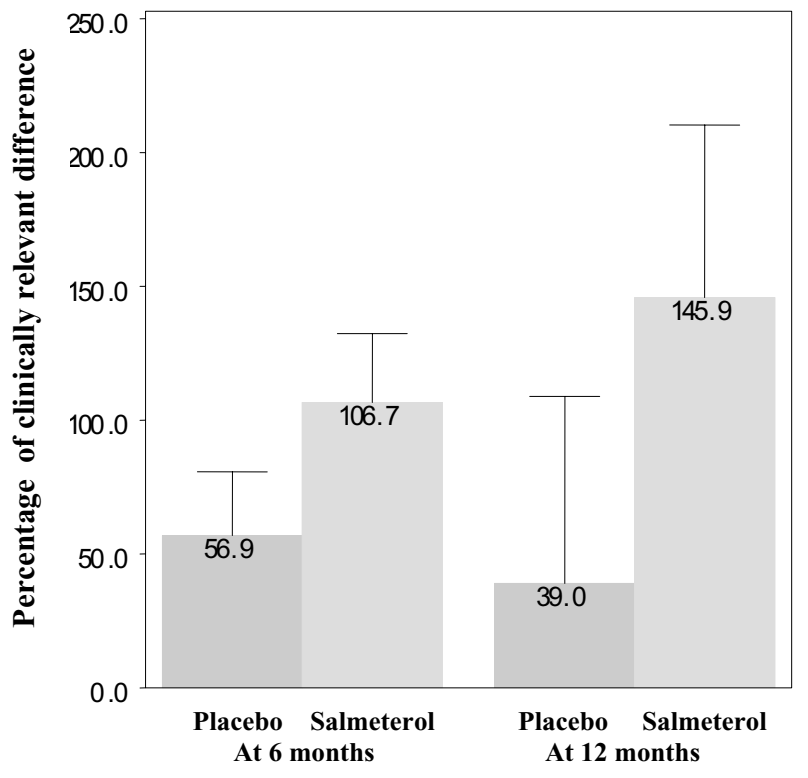

\section{Figure 6}

Percentage of clinically relevant difference in health status (change from baseline).

true extent of this benefit as a clinically relevant difference in health status has also been assessed and found to be greater with salmeterol.

The findings of the two populations analysed (Intent to Treat and Poorly Reversible) were consistent, indicating that the degree of reversibility to albuterol has little impact on response to salmeterol therapy, as reported previously [39]. There was some evidence of greater improvements in lung function with salmeterol treatment in those with better lung function at baseline, but all patients showed similar benefits in terms of exacerbation rate and health status. These findings suggest that salmeterol treatment is likely to benefit a wide spectrum of patients with COPD to a similar degree.

Recently, Salpeter et al. published the results of another meta-analysis of efficacy of various treatments in COPD [40]. Some of their conclusions appear initially to differ from ours, namely, that $\beta 2$-agonists were associated with more respiratory deaths, and led to no difference in severe exacerbations, compared with placebo. The apparent differences are likely to reflect differences in aim, methodology and timing of the analyses. We analysed data only from studies of salmeterol, whereas Salpeter's methodology allowed consideration of any $\beta 2$-agonist. In that analysis, most respiratory deaths $-60 \%$ of the weighting were from a single trial of formoterol, its erratum, and accompanying unpublished data [40]. Similarly, 98\% of the weighting for severe exacerbations was from a single study not included in our analysis. Thus, these results and ours presented here are not mutually contradictory.

It should be remembered that the underlying pathologies and concomitant medications in COPD and asthma are quite different. Nevertheless, recent major studies in asthma add to the body of knowledge about $\beta 2$-agonists. In the SMART study, conducted in asthma patients, there was no significant difference between salmeterol and placebo in the primary combined endpoint of respiratoryrelated deaths or life-threatening experiences [41]. Respiratory-related deaths, and asthma-related deaths, were slightly but significantly more frequent with salmeterol, but these differences were not apparent after a 6-month follow-up period. Similarly, a meta-analysis conducted in asthma patients (in which SMART data contributed $80 \%$ of the weighted data) identified a greater risk of life-threatening asthma attacks with $\beta 2$-agonists than placebo (6month risk difference $0.12 \% ; 95 \%$ CI $0.01-0.3 \%$ ) [42]. Comparisons with the current data however cannot be drawn.

COPD is a multi-component disease, associated with inflammation, airway obstruction, mucociliary dysfunction and structural changes in the lung. Consequently, it is logical to assume that interventions addressing these different components will be more effective than treatments having more limited scope. In addition to effects on bronchodilation, salmeterol may have other effects, including promotion of mucociliary clearance, protection against bacterial-mediated epithelial damage and antineutrophil effects $[43,44]$. Whether these additional effects play a role in the overall benefit of salmeterol therapy has yet to be determined. The analysis showed consistently greater efficacy of salmeterol than with placebo when added to usual therapy, which included inhaled and oral corticosteroids, anticholinergic agents, methylxanthines and mucolytics. Importantly, there were no apparent trends in relative efficacy for studies with and without these medications, despite the expectation that a "usual therapy" comparator group may reduce treatment differences. This suggests that these other interventions target different components to salmeterol in the underlying pathophysiology of the disease. However, insufficient detail was collected in the studies to allow this to be examined specifically.

Since the meta-analysis was performed, other completed, published studies have been identified which could have been included in the analysis. In a small population of patients with moderate COPD, salmeterol $(n=6)$ over 52 weeks reduced exacerbations and lung function when compared to placebo but was less beneficial than a combination of salmeterol and fluticasone propionate [45]. In 
addition, results from two studies comparing salmeterol with the long acting anticholinergic tiotropium over 26 weeks have been published [46]. It was felt that inclusion of these studies would not alter the conclusion of the study due to the small patient numbers and in addition, we did not have the individual patient data for the analysis.

\section{Conclusion}

In conclusion, this meta-analysis of nine large randomized clinical trials involving over 3500 patients in 34 countries has shown a consistent and highly statistically significant reduction in withdrawal rate from studies, reduction in exacerbation rate, improvement in lung function and improvement in health status with salmeterol compared with placebo/usual therapy, with no evidence of tachyphylaxis to bronchodilation over one year. The impact on a broad range of outcome measures suggests benefits from interventions for COPD that can modify more than one aspect of this multi-component disease.

\section{Competing interests}

RS has no competing interests. PW and MW are employees of GSK who sponsored this meta analysis.

\section{Authors' contributions}

RS was involved in the concept and planning of the meta analysis and in writing and editing the manuscript; PW and MW were involved in the writing and editing of the manuscript and responsible for the searches of the databases and the statistical analysis. All authors read and approved the final manuscript.

\section{Acknowledgements}

Financial support was provided by GlaxoSmithKline Research \& Development The authors would like to acknowledge the editorial assistance of Diane Storey. Accuhaler ${ }^{\mathrm{TM}}$, Diskus ${ }^{\mathrm{TM}}$ and Servent ${ }^{\mathrm{TM}}$ are trademarks of the GlaxoSmithKline group of companies.

\section{References}

I. Global Initiative for Chronic Obstructive Lung Disease (GOLD): Global strategy for the diagnosis, management and prevention of chronic obstructive pulmonary disease NHLBI/WHO workshop report. In Publication Number 270 I National Institutes of Health, National Heart Lung and Blood Institute; 200I.

2. Seemungal TA, Donaldson GC, Paul EA, Bestall JC, Jeffries DJ, Wedzicha JA: Effect of exacerbation on quality of life in patients with chronic obstructive pulmonary disease. Am J Respir Crit Care Med 1998, 157:1418-I422.

3. Wildman M, Groves J, Walia S, Stableforth D, Ayres J: Hospitalised COPD exacerbations: survival and univariate outcome predictors, 36-month follow-up [abstract]. Am J Respir Crit Care Med 2002, 165(2 pt 2):A272.

4. Niederman MS, McCombs JS, Unger AN, Kumar A, Popovian R: Treatment cost of acute exacerbations of chronic bronchitis. Clin Ther 1999, $21: 576-591$.

5. Murray C, Lopez A: Alternative projections of mortality and disability by cause 1990-2020: global burden of disease study. Lancet 1997, 349:|498-1504.

6. CPMP/EWA/562/98: Points to consider on clinical investigation of medicinal products in the treatment of patients with chronic obstructive pulmonary disease (COPD). 1999.
7. van Noord JA, de Munck DRAJ, Bantje ThA, Hop WC], Akveld MLM, Bommer AM: Long-term treatment of chronic obstructive pulmonary disease with salmeterol and the additive effect of ipratropium. Eur Respir J 2000, 15:878-885.

8. Rennard SI, Anderson W, ZuWallack R, Broughton J, Bailey W, Friedman M, Wisniewski M, Rickard K: Use of a long-acting inhaled $\beta_{2}$ adrenergic agonist, salmeterol xinafoate, in patients with chronic obstructive pulmonary disease. Am J Respir Crit Care Med 2001, 163:1087-1092.

9. Mahler DA, Donohue JF, Barbee RA, Goldman MD, Gross NJ, Wisniewski ME, Yancey SW, Zakes BA, Rickard KA, Anderson WH: Efficacy of salmeterol xinafoate in the treatment of COPD. Chest 1999, I I 5:957-965.

10. Boyd G, Morice AH, Pounsford JC, Siebert M, Peslis N, Crawford C: An evaluation of salmeterol in the treatment of chronic obstructive pulmonary disease (COPD). Eur Respir J 1997, 10:815-82|.

II. Mahler DA, Wire P, Horstman D, Change CN, Yates J, Fischer T, Shah $T$ : Effectiveness of fluticasone propionate and salmeterol combination delivered via the Diskus device in the treatment of chronic obstructive pulmonary disease. Am J Respir Crit Care Med 2002, 166: I084-1091.

12. Hanania NA, Darken P, Horstman D, Reisner C, Lee B, Davis S, Shah $\mathrm{T}$ : The efficacy and safety of fluticasone propionate $250 \mathrm{mcg} /$ salmeterol $50 \mathrm{mcg}$ combined in the Diskus inhaler for the treatment of chronic obstructive pulmonary disease. Chest 2003, 124:834-843.

13. Chapman KR, Arvidsson P, Chuchalin AC, Dhillon DP, Faurshou P, Goldstein R, Kuipers AF: The addition of salmeterol $50 \mathrm{mcg}$ bid to anticholinergic treatment in patients with COPD: a randomized placebo controlled trial. Can Respir J 2002, 9: I78-185.

14. Calverley PMA, Pauwels R, Vestbo J, Jones P, Gulsvik A, Anderson J, Maden C: Combined salmeterol and fluticasone in the treatment of chronic obstructive pulmonary disease: a randomized controlled trial. Lancet 2003, 361:449-456.

15. Stockley RA, Chopra NL, Rice on behalf of the SMS40026 Investigator group: Addition of salmeterol to existing treatment in patients with COPD: a 12 month study. Thorax 2006, 61:122-128.

16. Stockley R, Davis EA, Sondhi S, Rice L: Salmeterol provides sustained health status improvement over 12 months in patients with COPD [abstract]. Eur Respir J 2002, 20(suppl 38): 24 Is.

17. American Thoracic Society: Standards for the diagnosis and care of patients with chronic obstructive pulmonary disease (COPD). Am J Respir Crit Care Med 1995, 152:702-706.

18. Siafakas NM, Vermiere P, Pride NB, Paoletti P, Gibson J, Howard P: Optimal assessment and management of chronic obstructive pulmonary disease. The European Respiratory Society Task Force. Eur Respir J 1995, 8: 1398-I420.

19. Rodriguez-Roisin R: Toward a consensus definition for COPD exacerbations. Chest 2000, II 7:398S-40IS.

20. Jones PW, Quirk FH, Baveystock CM: The St George's Respiratory Questionnaire. Respir Med 199I, 85:25-3I.

21. Jones PW, Quirk FH, Baveystock CM, Littlejohns P: A self-complete measure of health status for chronic airflow limitation. The St George's Respiratory Questionnaire. Am Rev Respir Dis 1992, I 45: I321-1327.

22. Guyatt GH, Berman LB, Townsend M, Pugsley SO, Chambers LW: A measure of quality of life for clinical trials in chronic lung diseases. Thorax 1987, 42:773-778.

23. Jaeschke R, Singer J, Guyatt GH: Measurement of health status. Ascertaining the minimal clinically important difference. Controlled Clin Trials 1989, 10:407-4I5.

24. Mapel $D$, Pearson M: Obtaining evidence for use by healthcare payers on the success of chronic obstructive pulmonary disease management. Respir Med 2002, 96(Suppl C):S23-S30.

25. Ferguson GT, Funck-Brentano C, Fischer T, Darken P, Reisner C: Cardiovascular safety of salmeterol in COPD. Chest 2003, 123:1817-1824.

26. Tsagaraki V, Amfilochiou A, Markantonis SL: Evidence of tachyphylaxis associated with salmeterol treatment of chronic obstructive pulmonary disease patients. Int J Clin Pract 2006, 60:4I5-42I

27. Donohue JF, Menjoge S, Kesten S: Tolerance to bronchodilating effects of salmeterol in COPD. Respir Med 2003, 97:10I4-1020. 
28. Osman LM, Godden DJ, Friend JAR, Legge JS, Douglas JG: Quality of life and hospital readmission in patients with chronic obstructive pulmonary disease. Thorax 1997, 52:67-7I.

29. Spencer MD, Williams A: The health status burden of exacerbations in COPD measured using the EQ-5D [abstract]. Eur Respir J 2002, 20(Suppl 38):249s.

30. Seemungal TAR, Donaldson GC, Bhowmik A, Jeffries DJ, Wedzicha JA: Time course and recovery of exacerbations in patients with chronic obstructive pulmonary disease. Am J Respir Crit Care Med 2000, 161:1608-1613.

31. Donaldson GC, Seemungal TAR, Bhomik A, Wedzicha JA: Relationship between exacerbation frequency and lung function decline in chronic obstructive pulmonary disease. Thorax 2002, 57:847-852.

32. Garcia-Aymerich J, Monso E, Marrades RM, Escarrabill J, Felez MA, Sunyer J, Anto JM: Risk factors for hospitalisation for a chronic obstructive pulmonary disease exacerbation - EFRAM study. Am J Respir Crit Care Med 200I, 164:1002-1007.

33. Almagro P, Calbo E, Ochoa de Echaguen A, Barriero B, Quintana S, Heredia JL, Garau J: Mortality after hospitalization for COPD. Chest 2002, I 21: | 441-1448.

34. Anthonisen NR, Connett JE, Kiley JP, Altose MD, Bailey WC, Buist AS, Conway WA, Enright PL, Kanner RE, O'Hara P: Effect of smoking intervention and the use of an inhaled anticholinergic bronchodilator on the rate of decline of $F E V_{1}$ : the lung health study. JAMA 1994, 272:1497-I505.

35. Burge PS, Calverley PM, Jones PW, Spencer S, Anderson JA, Maslen TK: Randomized double blind, placebo controlled study of fluticasone propionate in patients with moderate to severe chronic obstructive pulmonary disease: the ISOLDE trial. BM] 2000, 320: I 297-I 303.

36. O'Donnell DE, Forkert L, Webb KA: Evaluation of bronchodilator responses in patients with "irreversible" emphysema. Eur Respir J 200I, 18:914-920.

37. Van der Molen T, Pieters W, Bellamy D, Taylor R: Measuring the success of treatment for chronic obstructive pulmonary disease - patient, physician and healthcare payer perspectives. Respir Med 2002, 96(SuppI C):SI7-S2I.

38. Jones PW: Interpreting thresholds for a clinically significant change in health status in asthma and COPD. Eur Respir J 2002, 19:393-404.

39. Cazzola M, Donner CF: Long-acting $\beta_{2}$-agonists in the management of stable chronic obstructive pulmonary disease. Drugs 2000, 60:307-320.

40. Salpeter SR, Buckley NS, Salpeter EE: Meta-analysis: anticholinergics, but not beta-agonists, reduce severe exacerbations and respiratory mortality in COPD. JGen Intern Med 2006, 21:10II-1019. Erratum in: J Gen Intern Med 2006, 21: II3I.

4I. Nelson HS, Weiss ST, Bleecker ER, Yancey SW, Dorinsky PM, SMART Study Group: The Salmeterol Multicenter Asthma Research Trial: a comparison of usual pharmacotherapy for asthma or usual pharmacotherapy plus salmeterol. Chest 2006, 129: 15-26. Erratum in: Chest 2006, 129: 1393.

42. Salpeter SR, Buckley NS, Ormiston TM, Salpeter EE: Meta-analysis: effect of long-acting beta-agonists on severe asthma exacerbations and asthma-related deaths. Ann Intern Med 2006 144:904-9|2.

43. Anderson R, Feldman C, Theron AJ, Ramalfi G, Cole PJ, Wilson R: Anti-inflammatory membrane-stabilizing interactions of salmeterol with human neutrophils in vitro. BrJ Pharmacol 1996, I 1 7:1387-1394.

44. Johnson M, Rennard S: Alternative mechanisms for long-acting $\beta_{2}$-adrenergic agonists in COPD. Chest 200 I, I 20:258-270.

45. Dal Negro RW, Pomari C, Tognella S, Micheletto C: Salmeterol \& Fluticasone $50 / 250 \mathrm{mcg}$ bid in combination provides a better long-term control than salmeterol $50 \mathrm{mcg}$ bid alone and placebo in patients already treated with theophylline. Pulm Pharmacol Ther 2003, 16:241-246.

46. Brusasco V, Hodder R, Miravitlles M, Korducki L, Towse L, Kesten S: Health outcomes following treatment for six months with once daily tiotropium compared with twice daily salmeterol in patients with COPD. Thorax 2003, 58:399-404.
Publish with Biomed Central and every scientist can read your work free of charge

"BioMed Central will be the most significant development for disseminating the results of biomedical research in our lifetime. "

Sir Paul Nurse, Cancer Research UK

Your research papers will be:

- available free of charge to the entire biomedical community

- peer reviewed and published immediately upon acceptance

- cited in PubMed and archived on PubMed Central

- yours - you keep the copyright

Submit your manuscript here:

http://www.biomedcentral.com/info/publishing_adv.asp
BioMedcentral 